() Царев В.Н., Митронин А.В., Подпорин М.С., Останина Д.А., Ипполитов Е.В., Митронин В.А. Федеральное государственное бюджетное образовательное учреждение высшего образования «Московский государственный медико-стоматологический университет имени А.И. Евдокимова» Министерства здравоохранения Российской Федерации. Москва, Россия

Резюме:

Цель. Определение возможных альтернативных алгоритмов дезинфекции корневых каналов путем комбинированного применения химических и физиотерапевтических методик ирригации в условиях in vitro. Материалыиметоды. Удаленныепоортодонтическимпоказаниямоднокорневыезубы использовалисьвкачестве подложки для формирования биопленки. Формирование смешанной биопленки осуществляется в несколько этапов, последовательно внося штаммы: Streptococcus sanguinis; Fusobacterium nucleatum; Porphyromonas gingivalis. Культивирование проводили в условиях текучих сред в анаэробных условиях, в течение 168 часов. После проведенного культивирования проводили обработку зубов с использованием: раствора хлоргексидина биглюконата 2\%; раствора гипохлорита натрия 3\%; фотодинамического воздействия с фотосенсибилизатором Fotoditazin; раствора гипохлорита натрия 1,0\% в комбинации с фотодинамическим воздействием. Оценку результатов проводили с использованием сканирующей электронной микроскопии.

Результаты. По результатам проведенной сканирующей электронной микроскопии были установлены различия между образцами контрольной группы и группы сравнения. Количество бактериальных клеток было значительно меньшим в группе сравнения, чем в контрольной, однако, во всех образцах, с разной степенью выраженности отмечалось наличиеучастков микробнойбиопленки. Вобразцах, где использовалисьстандартные концентрации отмечалось изменение ультраструктуры стенок дентинных канальцев с частичной ее деструкцией и обтурацией собственными фрагментами стенок с наличием микробных клеток. При использовании фотодинамического воздействия деструкции не наблюдалось. Микробный пейзаж имел сходный видовой состав, а фрагментов биопленки и отдельных клеток наблюдалось больше только в случае применения Фдт без комбинации с антисептиком.

Выводы. Комплексный подход к эндодонтическому лечению с использованием фотодинамической терапии совместно с антисептическими растворами в пониженных концентрациях позволяет добиться наилучшего эффекта эрадикации патогена по сравнению со стандартной хемомеханической методикой.

Ключевые слова: фотодинамическая терапия, хронический пульпит, гипохлорит натрия, корневые каналы, биопленка, сканирующая электронная микроскопия.

Статья поступила: 29.11.2020; исправлена: 09.01.2021; принята: 15.01.2021.

Конфликт интересов: Авторы декларируют отсутствие конфликта интересов.

Для цитирования: Царев В.Н., Митронин А.В., Подпорин М.С., Останина Д.А., Ипполитов Е.В., Митронин В.А. Комбинированное эндодонтическое лечение: микробиологические аспекты с использованием сканирующей электронной микроскопии. Эндодонтия today. 2021; 19(1):11-17. DOI: 10.36377/1683-2981-2021-19-1-11-17.

\title{
Combined endodontic treatment: microbiological aspects by using scanning electronical microscopy
}

\author{
( ) V.N. Tsarev, A.V. Mitronin, M.S. Podporin, D.A. Ostanina, E.V. Ippolitov, V.A. Mitronin. \\ Federal State Budgetary Educational Institution of the Higher Education \\ "A.I. Yevdokimov Moscow State University of Medicine and Dentistry" \\ of the Ministry of Healthcare of the Russian Federation, Moscow, Russia
}

\section{Abstract:}

Aim. To determine possible alternative algorithms for root canal disinfection through the combined use of chemical and physiotherapeutic irrigation techniques under in vitro conditions. 


\section{2 Исследования / Scientific researches}

Materials and methods. Single-root teeth removed according to orthodontic indications were used as a substrate for the formation of a biofilm. The formation of a mixed biofilm is carried out in several stages, successively introducing the following strains: Streptococcus sanguinis; Fusobacterium nucleatum; Porphyromonas gingivalis. Cultivation was carried out under fluid conditions under anaerobic conditions, for 168 hours. After the cultivation, the teeth were treated using: a solution of chlorhexidine bigluconate $2 \%$; a solution of sodium hypochlorite $3 \%$; photodynamic exposure with Fotoditazin photosensitizer; $1.0 \%$ sodium hypochlorite solution in combination with photodynamic exposure. The results were evaluated using scanning electron microscopy.

Results. The results of scanning electron microscopy revealed differences between the samples of the control group and the comparison group. The number of bacterial cells was significantly lower in the comparison group than in the control group, however, in all samples, the presence of microbial biofilm sites was noted with varying degrees of severity. In the samples where standard concentrations were used, there was a change in the ultrastructure of the walls of the dentine tubules with its partial destruction and obturation by its own fragments of the walls with the presence of microbial cells. When using the photodynamic effect of destruction was not observed. The microbial landscape had a similar species composition, and more fragments of biofilm and individual cells were observed only in the case of PDT without a combination with an antiseptic.

Conclusions. A comprehensive approach to endodontic treatment using photodynamic therapy together with antiseptic solutions in low concentrations allows us to achieve the best effect of pathogen eradication in comparison with the standard chemomechanical method.

Keywords: photodynamic therapy, chronic pulpitis, sodium hypochlorite, root canals, biofilm, scanning electron microscopy.

Received: 29.11.2020; revised: 09.01.2021; accepted: 15.01.2021.

Conflict of interests: The authors declare no conflict of interests.

For citation: V.N. Tsarev, A.V. Mitronin, M.S. Podporin, D.A. Ostanina, E.V. Ippolitov, V.A. Mitronin. Combined endodontic treatment: microbiological aspects by using scanning electronical microscopy. Endodontics today. 2021; 19(1):11-17. DOI: 10.36377/1683-2981-2021-19-1-11-17.

\section{АКТУАЛЬНОСТЬ}

Целью терапии корневых каналов является профилактика и лечение заболеваний пульпы и периапикальных тканей, а также создание условий для укрепления корней зуба. Результат эндодонтического лечения зависит от компетентности клинициста в проведении лечения без нарушения клинического протокола. Главной задачей лечения корневых каналов является профилактика апикального периодонтита и/или его излечивание, в том числе обеспечение контроля над инфекцией в результате соблюдения всех этапов инструментальной и медикаментозной обработки и гомогенной обтурации корневых каналов современными пломбировочными материалами [1]. Ошибки, возникающие на любом этапе лечения, включая диагностику, создание полости доступа, очистку, формирование и обтурацию корневых каналов, могут поставить под угрозу успех лечения. Например, создание «апикальной транспортации» приведет к очистке корневого канала, затрудняя борьбу с периапикальной инфекцией. Точно так же перфорация в области апикального отверстия или бифуркации может привести к инфицированию пародонта и альвеолярного отростка [2]. Показатель успешности первичного лечения корневых каналов при отсутствии апикального периодонтита в контролируемых условиях составляет от 90 до 95\%. Тем не менее, лечение апикального периодонтита составляет 24,5-65,8\% относительно всех процедур, проводимых врачами общего профиля [3].

Казалось бы, с появлением современных технологий с активным внедрением в стоматологическую практику инновационного оборудования и новейших материалов, средств для оказания качественной стоматологической помощи стало больше, однако, несмотря на внушительный набор современных методик лечения, частота распространенности и интенсивности эндо-периодонтальных осложнений остается важной проблемой терапевтической стоматологии.
Отчасти это связано с неправильной расстановкой приоритетов. При проведении эндодонтического лечения врач больше концентрирует свое внимание на двух, на его взгляд, основных осложнениях: на фрагментации инструмента при формировании корневых каналов и на возможной перфорации стенки корня. Однако, существенный процент осложнений связан с недостаточной медикаментозной обработкой и недопломбировкой системы корневых каналов.

Наиболее важным этапом в эндодонтической практике является ирригация, целью которой является максимально устранить микробную биопленку из пристеночного предентина, выстилающего корневой канал изнутри.

Традиционно предлагается множество соединений в водных растворах, которые используются в качестве ирригантов корневых каналов для удаления смазанного слоя, включая инертные вещества, такие как солевой раствор или кислоты (лимонная кислота, молочная кислота, дубильная кислота, полиакриловая кислота); хелатирующие растворы; природный полисахарид, например, 0,2\% хитозан; антибиотики широкого спектра действия (тетрациклины), а также различные соединения хлора [4].

Гипохлорит натрия - наиболее широко используемый в стоматологии антисептик группы галогенов. Применяется в концентрации от 0,5 до 5,25 \%. Этот ирригационный раствор предназначен для удаления некротизированных тканей с обработанных поверхностей дентина, благодаря чему он получил широкое применение для антисептической обработки корневых каналов.

Механизм действия гипохлорита натрия заключается в том, что он действует на жирные кислоты, превращая их в соли жирных кислот (мыло) и глицерол (спирт), которые уменьшают поверхностное натяжение оставшегося раствора. 
У начинающих специалистов большинство проблем, с которыми они сталкиваются при работе с гипохлоритом натрия, возникают из-за неправильного определения рабочей длины корневого пространства и/или чрезмерного

расширения апикального отверстия, боковой перфорации или заклинивания ирригационной иглы [5].

Данный антисептик обладает цитотоксическим действием, интенсивность которого возрастает с увеличением концентрации. Однако, присущий для данного препарата ключевой недостаток (цитотоксичность с повышением концентрации) обуславливает его пагубное действие на периапикальные ткани. Также к возможным осложнениям относятся некроз слизистой оболочки полости рта, развитие вторичной инфекции, кровотечение, появление парестезий. В литературе описаны случаи дисфункции лицевого нерва и развития хронического болевого синдрома.

Кроме того, одиночное использование раствора не обеспечивает полной антибактериальной очистки корневого канала и тотального удаления смазанного слоя, изменяет естественные свойства дентина.

Новые технологии беспрерывно интегрируются в стоматологическую практику. Совершенствуются давно известные антисептические средства для эндодонтического лечения и разрабатываются новые рецептуры для ирригации корневых каналов, а также способы их применения [6]. Каждый из используемых в практике средств обладает целым спектром как положительных, так и отрицательных качеств, что указывает на необходимость совершенствования самой технологии медикаментозной обработки системы корневых каналов с последующей апробацией на практике и проведением сравнительных исследований, базируясь на основах доказательной медицины [7].

В связи с этим актуальной задачей в стоматологии остается профилактика, своевременное и качественное лечение пульпита, а также предотвращение рецидивов заболевания. Совершенствуя комплексную диагностику и терапию современными способами лечения, необходимо четко понимать обоснованность применения новых методик и алгоритм их проведения с учетом этиологических и патогенетических факторов развития болезни.

\section{ЦЕЛЬ ИССЛЕДОВАНИЯ}

Определение возможных альтернативных алгоритмов дезинфекции корневых каналов путем комбинированного применения химических и физиотерапевтических методик ирригации в условиях in vitro.

\section{МАТЕРИАЛЫ И МЕТОДЫ}

Для проведения экспериментального исследования использовали удаленные по ортодонтическим показаниям однокорневые зубы, которые в дальнейшем применяли в качестве подложки для формирования микробной биопленки. Перед постановкой эксперимента исследуемые удаленные зубы были эндодонтически пролечены с учетом определения рабочей длины корневых каналов для предотвращения выведения кончика инструмента за апикальное отверстие. Далее, с помощью алмазного диска проводили сепарацию зуба продольно через центр канала в щечно-язычном направлении. На внешнюю поверхность зуба по линии распила наносили насечки, которые использовались для последующего точного сопоставления двух половин. В качестве разделителя на зуб наносили тонкий слой стерильного глицерина, после чего фиксировали в силиконовом оттискном материале для получения «формы-ключа», которая использовалась для точной фиксации и удержания зуба в вертикальном положении в момент его дальнейшей обработки после культивирования с микробной взвесью.

Используя стерильный эндодонтический шприц, бактериальную взвесь из чистой культуры концентрацией $10^{6}-10^{8} \mathrm{KOE} / \mathrm{M}$, разведенную в жидкой питательной среде (BHI, LIM или AC) с необходимыми ростовыми добавками, помещали на каждую из подготовленных половин зуба. Формирование смешанной биопленки осуществляется в несколько этапов: на начальном этапе производится внесение микроба с высокой адгезивной активностью - Streptococcus sanguinis с последующим культивированием 24 часа, на следующем этапе, спустя еще 12 часов, проводят внесение представителя промежуточных колонизаторов - Fusobacterium nucleatum. На заключительном этапе формирования смешанной микробной биопленки вносят представителя красного комплекса пародонтопатогенов - Porphyromonas gingivalis.

Каждый из исследуемых образцов помещался в стерильную невентилируемую чашку Петри диаметром 100 мм и фиксировался в горизонтальном положении с помощью липкого воска. Чашка Петри заполнялась на $1 \frac{1}{4}$ питательным бульоном для культивирования анаэробов с витамином К и гемином, плотно закрывалась крышкой и помещалась в микроанаэростат HiAnaerobic System Mark V (Himedia, Индия) с постоянным составом бескислородной газовой смеси, состоящей из 80\% азота, 10\% водорода, 10\% углекислого газа, который в свою очередь устанавливался в шейкер-инкубатор ES-20 (BioSan, Латвия), обеспечивающий возвратно-поступательные движения в диапазоне 120 движений в минуту, формируя условия текучих сред. Время культивирования биопленки - 168 часов при температуре $37^{\circ} \mathrm{C}$ с промежуточным восполнением питательной активности омываемого бульона.

После проведенного культивирования половинки зубов исследуемых образцов соединяли между с собой и фиксировали в вертикальном положении, используя заранее подготовленную силиконовую форму-ключ. Всего было смоделировано пять эталонных моделей зубов с подготовленным магистральным каналом на этапе химической и физиотерапевтической обработки.

Обработка магистрального канала проводилась по следующим протоколам:

- группа контроля: 1 - медикаментозная обработка с использованием раствора хлоргексидина биглюконата 2\%; 2 - медикаментозная обработка с использованием раствора гипохлорита натрия 3\%;

- группа сравнения: 3 - медикаментозная обработка с использованием методики фотодинамического воздействия с фотосенсибилизатором Fotoditazin; 4 - медикаментозная обработка с использованием гипохлорита натрия 1,0\% (экспозиция 10 минут) в комбинации с фотодинамическим воздействием, с предварительной ультразвуковой активацией антисептика и фотосенсибилизатора.

После проведенной медикаментозной обработки образцы фиксировались в формалине и помещались в стерильные контейнеры для дальнейшего проведения сканирующей электронной микроскопии (СЭМ).

Перед проведением СЭМ, фиксированные в формалине спилы зубов извлекались из контейнеров, вы- 


\section{4 Исследования / Scientific researches}

сушивались при комнатной температуре в течение 10 минут, монтировались на предметные стекла и алюминиевые столики с помощью угольного клея и напылялись золотом (толщина слоя 10 нм) в установке «SPIMODULE Sputter Coater» (SPI Supplies, США) (рис. 1).

Исследование было проведено с помощью сканирующего двулучевого электронного микроскопа Quanta 200 3D (FEl Company, CША) в режиме высокого вакуума при ускоряющем напряжении 10 кВ (рис. 2).

Для статистической обработки данных исследования использовался лицензионный пакет IBM SPSS Statistics v 22.0 (IBM, Чикаго, Иллинойс, США). Для обработки полученных данных использовался метод описательной статистики.

\section{РЕЗУЛЬТАТЫ ИССЛЕДОВАНИЯ}

По результатам проведенной сканирующей электронной микроскопии были установлены различия между образцами контрольной группы и группы сравнения. Бактериальные клетки, как в образцах контрольной группы, так и в группе сравнения, отличались полиморфизмом. Признаки деления были сохранены.

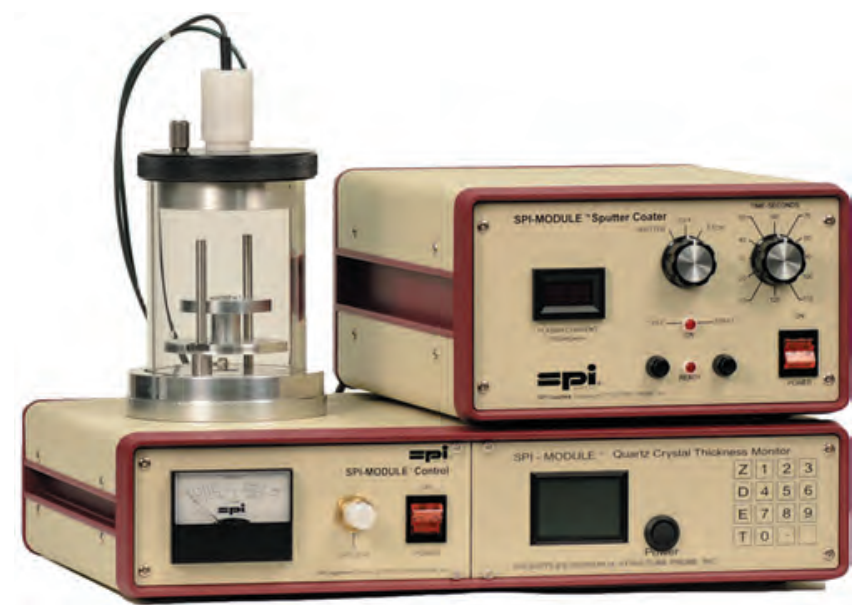

Рис. 1. Модульный распылитель «SPI-MODULE Sputter Coater" (SPI Supplies, США)" для создания золотого напыления при СЭМ

Fig. 1. SPI-MODULE Sputter Coater (SPI Supplies, USA) "for creating gold sputtering at SEM

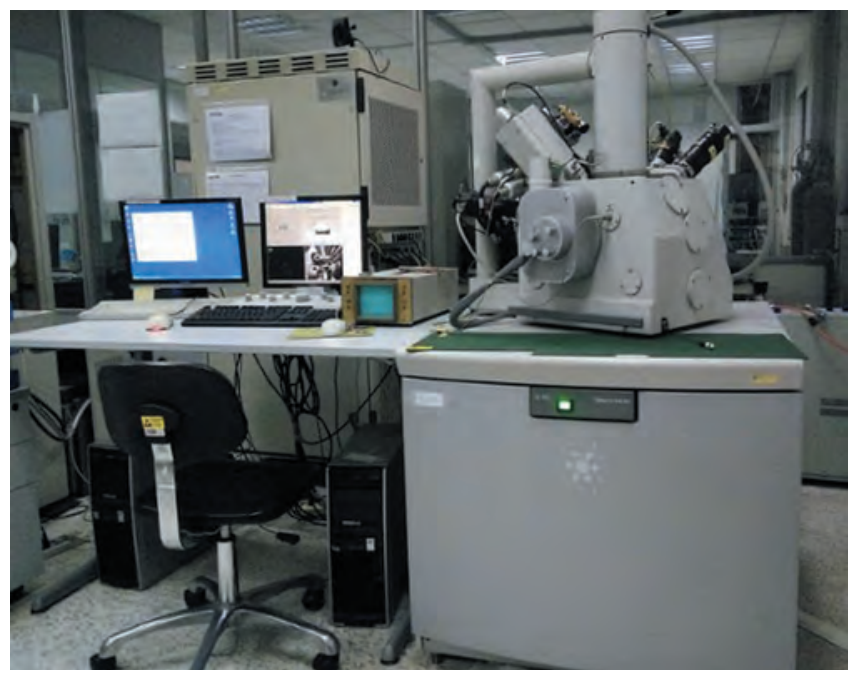

Рис. 2. Сканирующий электронный микроскоп Quanta 200 3D (FEI Company, СШA)

Fig. 2. Scanning electron microscope Quanta 200 3D (FEI Company, USA)

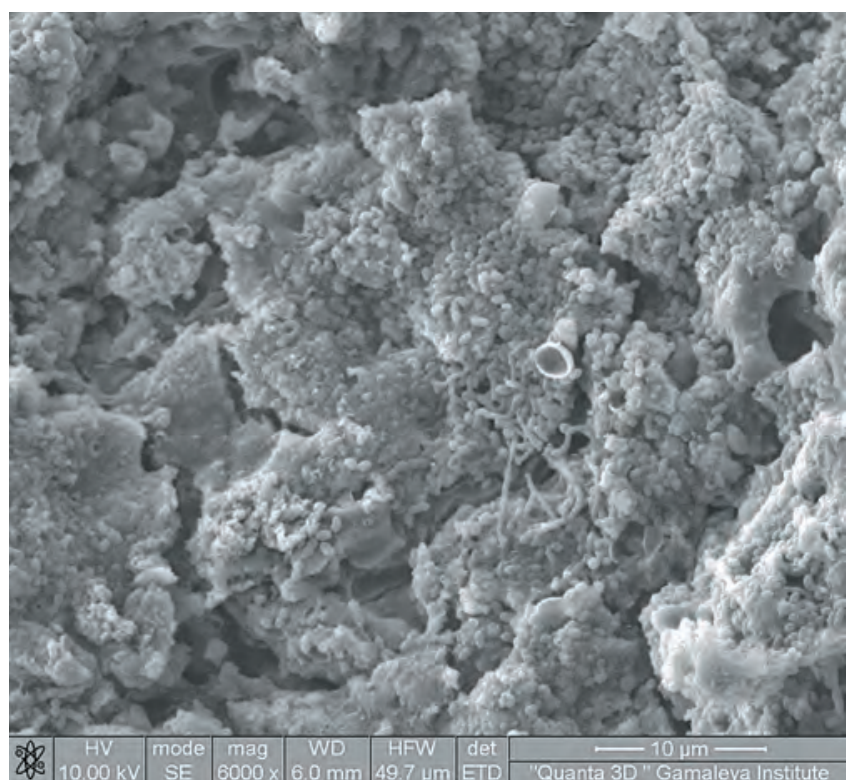

Рис. 3. Моделирование смешанной

биоплёнки in vitro: фрагмент биоплёнки с выраженной мантией и свободно лежащими бактериальными клетками. СЭМ Ув. 6000x

Fig. 3. Simulation of a mixed biofilm in vitro: a fragment of a biofilm with a pronounced mantle and free-lying bacterial cells. SAM Uv. 6000x

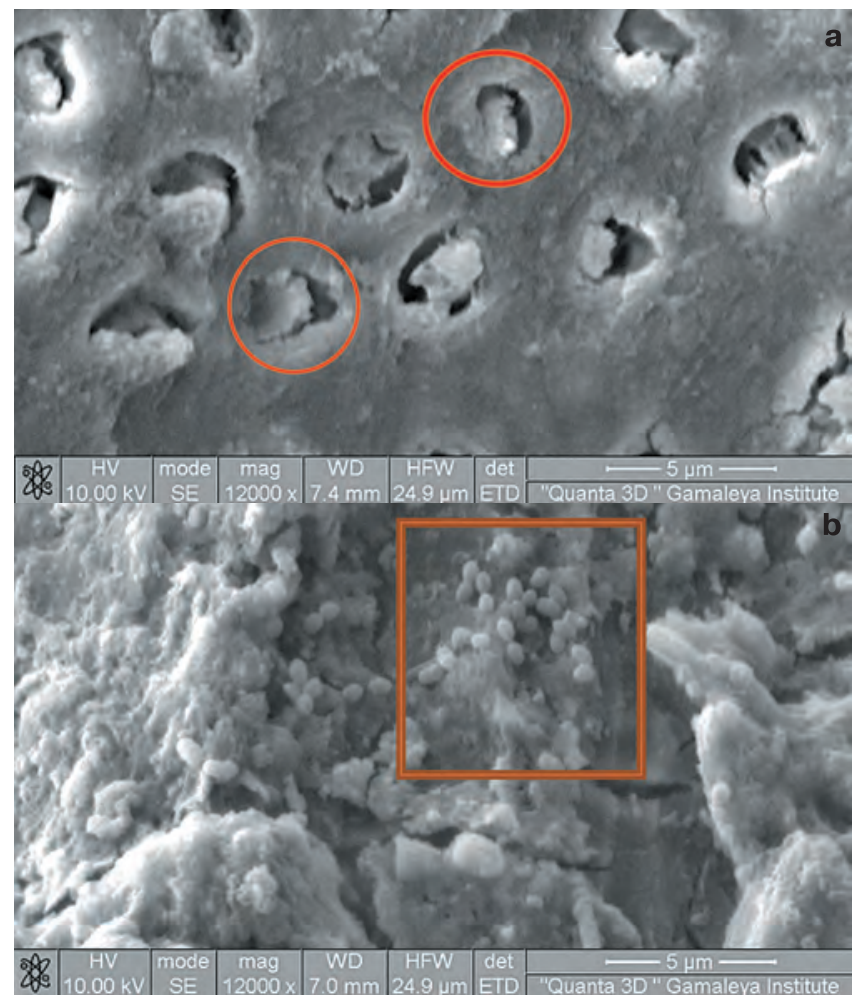

Рис. 4. а - Дентинные канальцы. Общий вид. Ув. 12000x. Обработка - хлоргексидин биглюконата 2\%; b - Фрагмент деструкции стенки дентинных канальцев. Ув. 12000x. Обработка - хлоргексидин биглюконата $2 \%$

Fig. 4. a - The dentinal tubules. General view. Uv. 12000x. Treatment - chlorhexidine bigluconate $2 \%$; b - Fragment of destruction of the wall of the dentine tubules. Uv. 12000x. Treatment - chlorhexidine bigluconate $2 \%$ 


\section{Исследования / Scientific researches}

Фрагменты биопленки имели характерную ультраструктуру. На твердых поверхностях образцов состояли из бактериальных клеток и экстрацеллюлярного матрикса.

В целом, с определенной достоверностью можно сказать, что в образцах группы сравнения, количество бактериальных клеток было значительно меньшим, чем в контрольной группе. Однако, во всех образцах, с разной степенью выраженности отмечалось наличие либо участков микробной биопленки, либо отдельных бактериальных клеток, что не позволяло говорить о полноценной микробной эрадикации. К примеру, на рисунке 3 отмечается наличие овоидных палочек, в редких случаях объединённые в кластеры, но при этом не наблюдалось наличие микробного матрикса. Особое внимание стоит уделить ультраструктуре дентинных канальцев: в образцах, где использовались стандартные концентрации антисептиков (образец №1 и
№2) отмечалось изменение ультраструктуры стенок с частичной ее деструкцией (рис. 4 и рис. 5). В некоторых участках исследуемых спилов зубов дентинные канальцы были почти полностью обтурированы собственными фрагментами стенок, что при наличие определенной степени микробной контаминации способствовало повторному формированию микробной биопленки.

При использовании фотодинамического воздействия подобной деструкции не наблюдалось. Микробный пейзаж имел сходный видовой состав, а фрагментов биопленки и отдельных клеток наблюдалось больше только в том варианте обработки, где применение ФДт было без комбинации с антисептиком (рис. 6). Гипохлорит натрия в пониженной концентрации до 1\% не оказывал деструктивного воздействия в отношении стенок дентинных канальцев, и в совокупности с фотодинамическим воздействием достигалось повышение
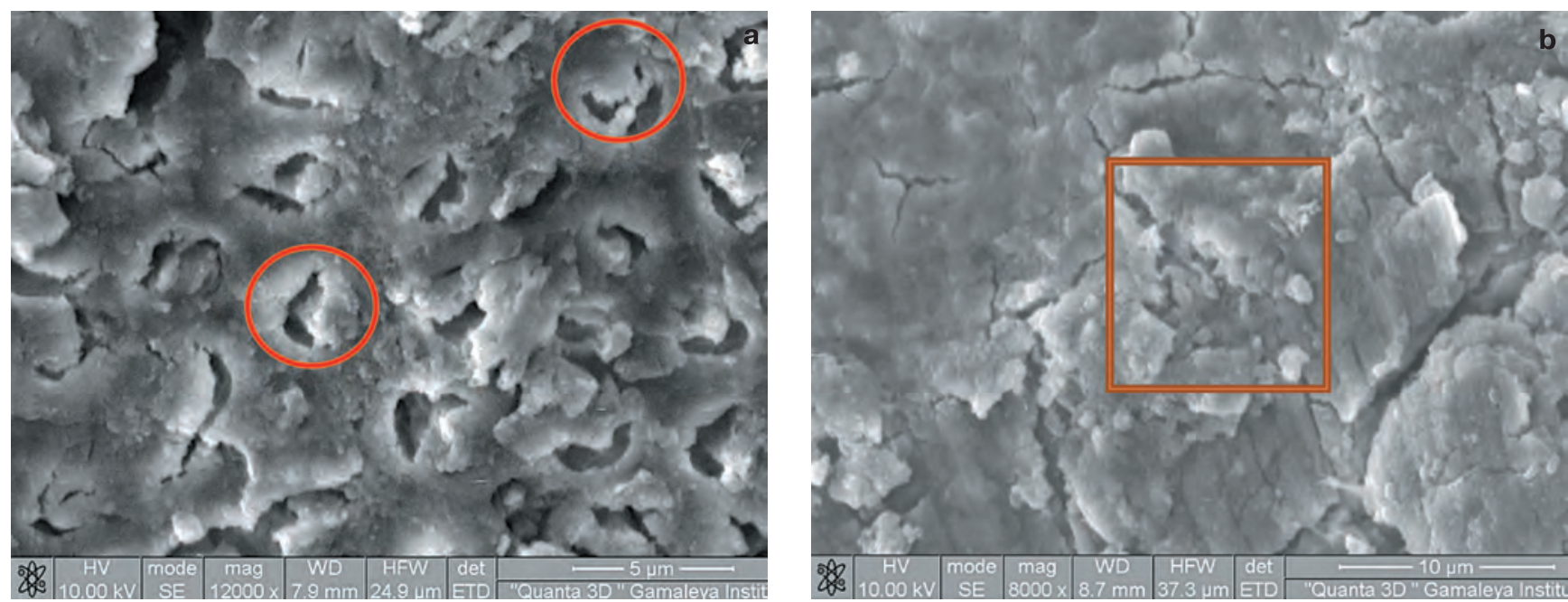

Рис. 5. a - Дентинные канальцы. Общий вид. Ув. 12000x. Обработка - гипохлорит натрия 3\%; b Фрагмент деструкции стенки дентинных канальцев. Ув. 12000х. Обработка - гипохлорит натрия 3\%

Fig. 5. a - The dentinal tubules. General view. Uv. 12000x. Treatment - sodium hypochlorite $3 \%$; b - Fragment of destruction of the wall of the dentine tubules. Uv. 12000x. Treatment - sodium hypochlorite $3 \%$
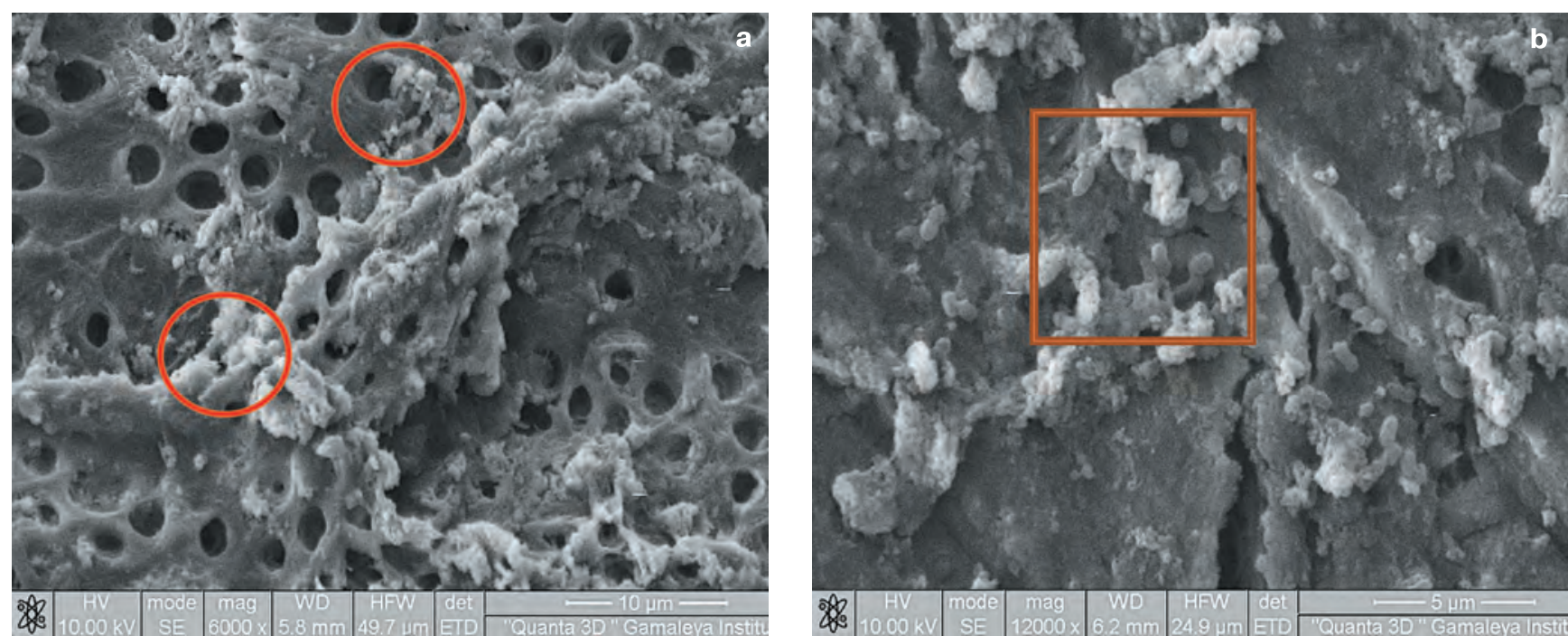

Рис. 6. а-Дентинные канальцы. Общий вид. Ув. 8000х. Обработка - ФДТ с ФС Fotoditazin; b - Фрагменты отдельных компонентов микробной биопленки. Ув. 12000x. Обработка - ФДТ с ФС Fotoditazin

Fig. 6. a - Dentine tubules. General view. Uv. 8000x. Processing - PDT with FS Fotoditazin; b - Fragments of individual components of the microbial biofilm. Uv. 12000x. Processing - PDT with FS Fotoditazin 


\section{6 Исследования / Scientific researches}

синергетического эффекта в отношении микробной эрадикации (рис. 7).

Применение ультразвуковой активации фотосенсибилизатора позволило достичь более эффективного действия заявленного алгоритма обработки магистрального канала. Формируемый при этом положительный эффект заключался в устойчивой однонаправленной циркуляции жидкости вблизи небольшого вибрирующего объекта. Возникновение множественных вихревых токов (самые быстрые из которых наблюдаются у верхушки ультразвукового эндодонтического инструмента) формировало прямой поток жидкости. Такой звуковой микростриминг способствует полноценному преодолению фотосенсибилизатором осложненной структуры дентинных канальцев, в следствие проведенной предварительной механической обработки, а также физическому устранению бактерий и элементов микробной биопленки.

Стоит отметить, что полной эрадикации патогенов при сонофотодинамической терапии (СФДТ) также не наблюдалось (рис. 7б). В данном случае это связано с тем, что бактериальные клетки способны избирательно адсорбировать и накапливать молекулы фотосенсибилизатора. Однако, сохраненная структура стенок дентинных канальцев способствовала более свободному проникновению светопоглощающих растворов в глубину, и в комбинации с антисептиком позволило достичь лучшей степени очистки.

\section{ОБСУЖДЕНИЕ}

Необратимые формы пульпита с развитием колонизации микробной флоры при некрозе пульпы приводят к инфицированию не только системы корневых каналов, но и периодонта. Анатомическая близость мест скопления микроорганизмов к кровеносному руслу это условие, способствующее развитию бактериемии, в частности у пациентов с иммунодефицитным состоянием организма. Учитывая сложные морфологические особенности строения системы корневых каналов, современная эндодонтическая практика должна постоянно пополняться новыми методиками лечения и профилактики этиологических и патогенетических факторов болезни. Появление множества различных

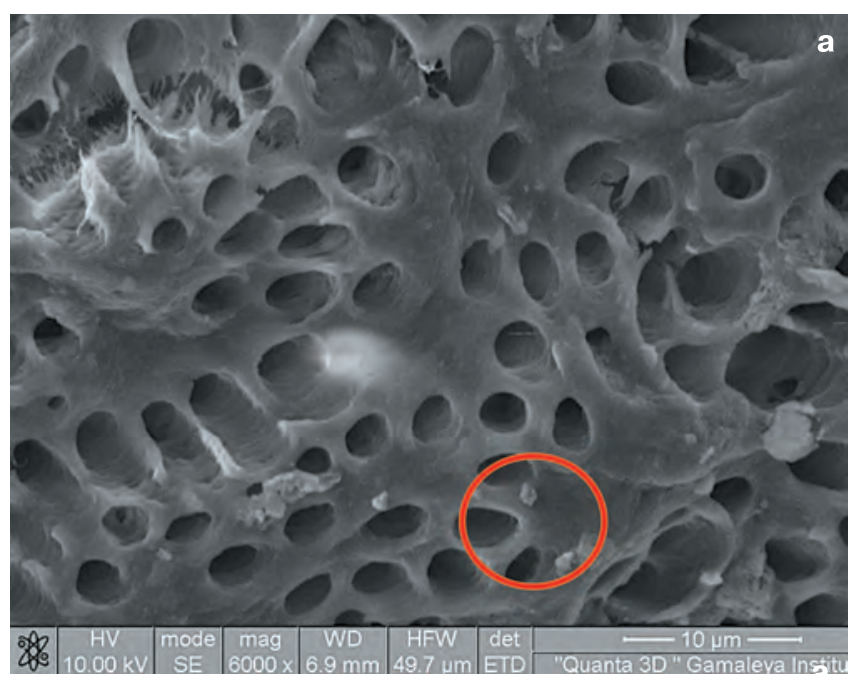

инструментов и препаратов, помогающих провести качественное эндодонтическое вмешательство, в ряде случаев облегчили и усовершенствовали стандартные методики лечения, однако, стоит понимать, что у любого нового или альтернативного метода лечения должны быть свои показания и алгоритм применения.

Основной этиологической причиной воспаления в пульпе является полибактериальная флора. Присутствует выраженное преобладание стрептококковой флоры над стафилококковой в процессе возникшего воспаления, а новые технологии в анаэробном культивировании позволили более детально охарактеризовать микробный фон данной нозологии, тем самым существенно расширить спектр выделяемых микроорганизмов. Основу составляют бактерии: до 50\% грамположительные кокки; 20-25\% грамотрицательные анаэробные кокки; 20-25\% - грамположительные палочки; около 10\% - грамотрицательные неспоровые анаэробы; а также грибы рода Candida spp.

Таким образом, этап дезинфекционной обработки системы корневых каналов является важным и основополагающим моментом успешного лечения. Применение различных антисептических препаратов и их комбинация между собой, применение альтернативных способов эрадикации патогена и использование новейших схем и протоколов лечения - все это необходимо применять с обязательным учетом микробного консорциума, который является индивидуальным в каждом конкретном случае.

Что касается фотодинамического воздействия, на данный момент в результате проведенных нами исследований стало ясно, что сложившиеся реалии о том, что данную методику возможно использовать стандартизировано при любой нозологии - преждевременное заключение. Не каждый фотосенсибилизатор способен должным образом адсорбироваться и накапливаться в бактериальной клетке, тем самым проявляя обоснованный положительный результат.

Полностью отказываться от применения антисептических препаратов, не представляется возможным, однако, снижение их используемой концентрации, использование комбинаций антисептиков и совместное примене-

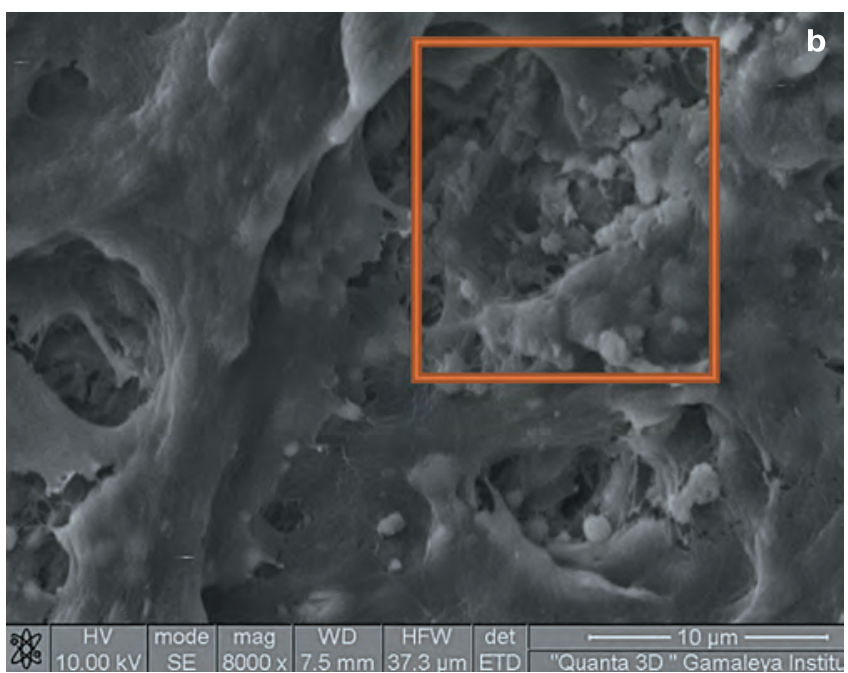

Рис. 7. а - Дентинные канальцы. Общий вид. Ув. 8000х. Обработка - гипохлорит натрия $1 \%+$ ФДт с ФC Fotoditazin; b - Фрагменты отдельных компонентов микробной биопленки. Ув. 8000х.

Обработка - гипохлорит натрия $1 \%+$ ФДТ с ФС Fotoditazin

Fig. 7. a - Dentine tubules. General view. Uv. 8000x. Treatment - Sodium hypochlorite $1 \%+$ PDT with FS Fotoditazin; b - Fragments of individual components of the microbial biofilm. Uv. 8000x. Treatment Sodium hypochlorite 1\% + PDT with FS Fotoditazin 


\section{Исследования / Scientific researches}

ние с альтернативными способами дезинфекции и стерилизации каналов является актуальным направлением в котором должна двигаться современная эндодонтия.

\section{выводы}

1. Эффективность эндодонтического лечения зависит от особенностей состава микробной биоплёнки системы корневых каналов и может быть повышена за счёт применения новых технологий, включающих физические, химические и механические воздействия, а также их сочетания (хемомеханическая обработка, антисептики направленного действия, фотодинамическое и ультразвуковое воздействия).

\section{СПИСОК ЛИТЕРАТУРЫ:}

1. Митронин А.В., Собкина Н.А., Помещикова Н.И., Дмитриева Л.А. Использование компьютерной микротомографии для оценки качества эндодонтической обработки зуба при использовании современных инструментов. Эндодонтия today. 2018.1:22-26.

2. Eleftheriadis GI, Lambrianidis TP. Technical quality of root canal treatment and detection of iatrogenic errors in an undergraduate denta clinic. Int Endontic J. 2005;38(10):725-34.

3. Alrahabi M, Younes $\mathrm{H}$. A cross-sectional study of the quality of root canal treatment in Al-Madinah Al-Munawwarah. Saudi Endod J. 2016;6(1):31-5.

\section{REFERENCES:}

1. Mitronin A.V., Sobkina N.A., Pomeshchikova N.I., Dmitrieva L.A. The use of computer microtomography to assess the quality of endodontic tooth processing using modern tools. Endodontiya today 2018.1:22-26.

2. Eleftheriadis GI, Lambrianidis TP. Technical quality of root canal treatment and detection of iatrogenic errors in an undergraduate dental clinic. Int Endontic J. 2005;38(10):725-34

3. Alrahabi M, Younes $H$. A cross-sectional study of the quality of root canal treatment in Al-Madinah Al-Munawwarah. Saudi Endod J. 2016;6(1):31-5.

\section{ИНФОРМАЦИЯ ОБ АВТОРАХ:}

Царев В.Н. - директор научно-исследовательского медико-стоматологического института, заведующий кафедрой микробиологии, вирусологии, иммунологии, доктор медицинских наук, профессор, Заслуженный работник высшей школы PФ, ORCID ID: 0000-0002-3311-0367.

Митронин А.В. - профессор, доктор медицинских наук, декан стоматологического факультета МГМсу, заведующий кафедрой кариесологии и эндодонтии, Заслуженный врач PФ, ORCID ID: 0000-0002-3561-6222.

Подпорин М.C. - научный сотрудник лаборатории молекулярно-биологических исследований научно-исследовательского медико-стоматологического института, ORCID ID: 0000-0001-6785-0016.

Останина Д.А. - ассистент кафедры кариесологии и эндодонтии, ORCID ID: 0000-0002-5035-5235.

Ипполитов Е.В. - профессор кафедры микробиологии, вирусологии, иммунологии, доктор медицинских наук, профессор, ORCID ID: 0000-0003-1737-0887.

Митронин B.A. - доцент кафедры ортопедической стоматологии и гнатологии, кандидат медицинских наук, доцент, ORCID ID: 0000-0003-2446-155X.

Федеральное государственное бюджетное образовательное учреждение высшего образования «Московский государственный медико-стоматологический университет имени А.И. Евдокимова» Министерства здравоохранения Российской Федерации. Москва, Россия.

\section{AUTHOR INFORMATION:}

V.N. Tsarev - Director of the Research Institute of Medicine and Dentistry, Head of the Department of Microbiology, Virology, and Immunology. Doctor of Medical Sciences, Professor, Honored Worker of the Higher School of the Russian Federation, ORCID ID: 0000-0002-3311-0367.

A.V. Mitronin - Head of the Department of Cariesology and Endodontics, Doctor of Medical Sciences, Professor, Honored Doctor of the Russian Federation, ORCID ID: 0000-0002-3561-6222.

M.S. Podporin - Researcher at the Laboratory of Molecular Biological Research of the Research Institute of Medicine and Dentistry, ORCID ID: 0000-0001-6785-0016.

D.A. Ostanina - Assistant of the Department of Cariesology and Endodontics, ORCID ID: 0000-0002-5035-5235.

E.V. Ippolitov - Professor of the Department of Microbiology, Virology, Immunology, Doctor of Medical Sciences, Professor, ORCID ID: 0000-0003-1737-0887.

V.A. Mitronin - associate Professor of the Department of prosthodontics and gnatologia candidate of medical Sciences, associate Professor, ORCID ID: 0000-0003-2446-155X.

Federal State Budgetary Educational Institution of the Higher Education "A.I. Yevdokimov Moscow State University of Medicine and Dentistry" of the Ministry of Healthcare of the Russian Federation, Moscow, Russia. 